\title{
COMPARISON OF 2D AND 3D LARGE SCALE MORPHOLOGICAL MODELING OF OFFSHORE WIND FARMS USING HPC
}

\author{
Elizabeth Christie ${ }^{1}$, Ming $\mathrm{Li}^{2}$ and Charles Moulinec ${ }^{3}$
}

\begin{abstract}
The rapidly developing offshore wind farm sector has increased the need to understand if wind farm placement and design has any impact on large scale coastal processes. This paper looks at high resolution hydrodynamic and morphological modeling of offshore wind farms in both 2D and 3D to determine whether either model is capable of representing complex flow patterns around monopile structures and subsequent sediment transport.
\end{abstract}

Keywords: offshore wind farm; TELEMAC; coastal modeling

\section{INTRODUCTION}

With recent increased development of Offshore Wind Farms (OWF), it is important to determine any impact they have on large scale coastal hydrodynamics and morphodynamics for coastal management.

It is well established, Whitehouse (1998), Sumer \& Fredsøe (2002) that wind turbine monopiles modify the localized hydrodynamics to create a complex 3D flow structure of vortices, which results in scour hole formation. Currently modeling the coastal scale impact of the OWF often involves parameterization of these localized effects, typically by including a resistance term at point locations to represent the structure (Lambkin et al. 2009). This process often means that structures are not identified in the computational mesh. The flow is oversimplified as 3D vortices are not explicitly included in the model results, with the consequence that sediment transport is not accurately represented.

The present research intends to determine whether high resolution large scale modeling of OWF's with the structure represented is capable of adequately describing the complex near field flow and its effect on sediment dynamics by comparing 2D and 3D large scale morphological models.

\section{METHODS}

Liverpool Bay (Figure 1) located in the Eastern Irish Sea, has been selected as a test bed. Within Liverpool Bay are three OWF's; Burbo Bank, North Hoyle and Rhyl Flats, consisting of 25, 30 and 25 monopile turbines respectively, with a diameter of $4-5 \mathrm{~m}$. Liverpool Bay is tidal dominated with a peak tidal range of $10 \mathrm{~m}$ with strong currents and waves (Polton et al. 2011). The sediment dynamics are strongly affected by the hydrodynamics, with the Mersey estuary acting as a sediment sink.

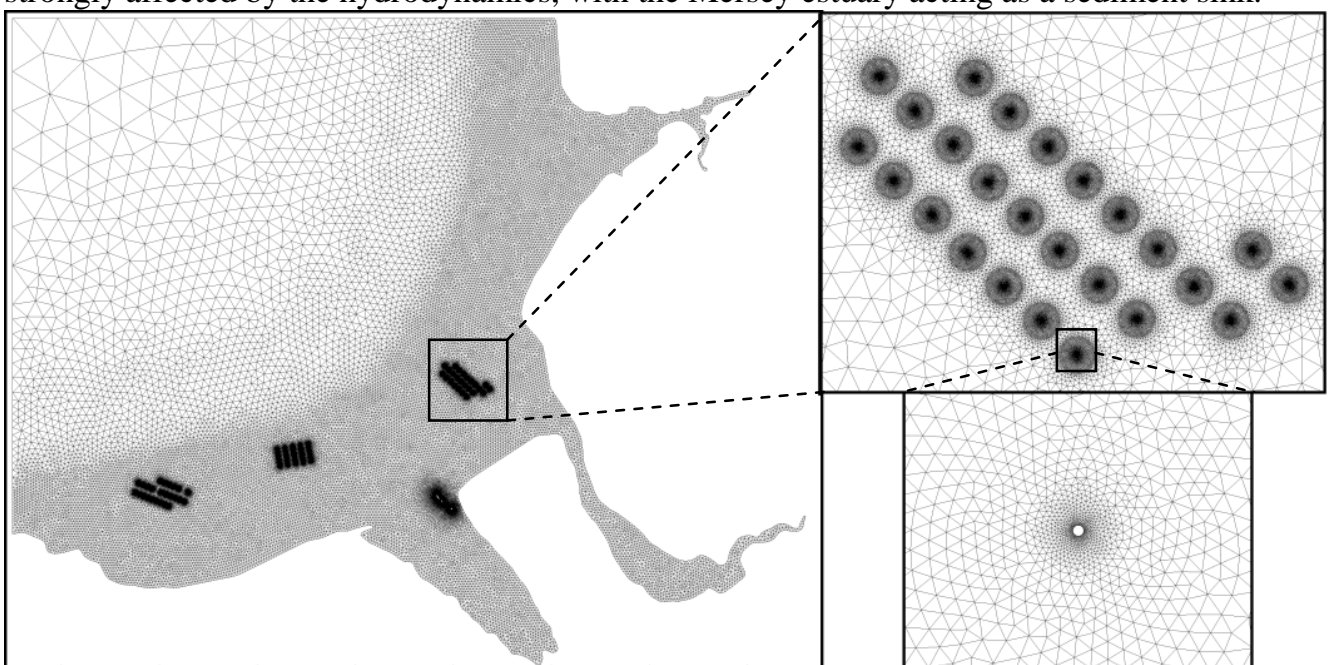

Figure 1. High resolution Liverpool Bay mesh, with wind farm locations highlighted (Burbo Bank, North Hoyle, Rhyl Flats). The mesh is comprised of 325,000 elements in 2D.

\footnotetext{
${ }^{1}$ Department of Engineering, University of Liverpool, Brownlow Hill, Liverpool, L69 3GH, UK

2 Department of Engineering, University of Liverpool, Brownlow Hill, Liverpool, L69 3GH, UK

${ }^{3}$ Science and Technology Facilities Council, Daresbury Laboratory, Daresbury Science and Innovation Campus, Warrington, Cheshire, WA4 4AD, UK
} 
The TELEMAC modeling system, which consists of a hydrodynamic module TELEMAC 2D/3D, together with sediment transport module SISYPHE, was used to model Liverpool Bay. The finite element method was used to solve the equation system. The mesh (Figure 1) used consists of approximately 325,000 elements for the $2 \mathrm{D}$ case in order to represent the structure detail. The monopole turbines are represented as an island in the grid with concentric rings of increasing mesh size for detailed resolution. For the 3D case the water column is divided into 10 equal height depth layers, creating a mesh of approximately 3.25 million elements for the required vertical resolution.

Boundary conditions used include offshore open boundary with the tidal water level or riverine discharge specified and solid wall shoreline boundaries. The model is driven by scaled representative tides calculated by the Tidal Model Driver (Egbert \& Erofeeva, 2002) for 7 tidal constituents (M2, S2, $\mathrm{N} 2, \mathrm{~K} 2, \mathrm{P} 1, \mathrm{O} 1, \mathrm{~K} 2)$. Riverine discharge is also included as a model input with annual mean flow rate specified at the boundaries of the Dee, Mersey, Douglas and Ribble estuaries as $33.70 \mathrm{~m}^{3} / \mathrm{s}, 37.22 \mathrm{~m}^{3} / \mathrm{s}$, $4.16 \mathrm{~m}^{3} / \mathrm{s}, 33.04 \mathrm{~m}^{3} / \mathrm{s}$ respectively. The Smagorinsky turbulence model is used for horizontal turbulent modeling with the mixing length model used for vertical turbulence in the $3 \mathrm{D}$ case. Bottom friction is calculated by the Chézy formula with a Chézy coefficient of 24. Sediment transport is modeled with the Meyer-Peter bed load transport formula with a single sediment size class of diameter $0.23 \mathrm{~mm}$, and the morphology is updated with the Exner equation.

The model is run for both 2D and 3D cases over a full spring-neap cycle. To cope with the large computational mesh sizes, the TELEMAC system is run in parallel using the facility at Liverpool University and HECToR. Previous tests on similar size mesh have shown good performance in scaling, Moulinec et al. (2011).

Model results were calibrated against available coastal tide gauge data (Figure 2) at 4 locations in Liverpool Bay; Llandudno, Gladstone dock, Hilbre Island and Alfred Dock. The model free surface elevation shows good agreement with the tide gauge data over the tidal cycle in all 4 locations. Some phase shifting is seen at the Alfred Dock site, which is likely due to the fact that it is located at a shallow depth and the uncertainties in local bathymetry plays significant role.

a)

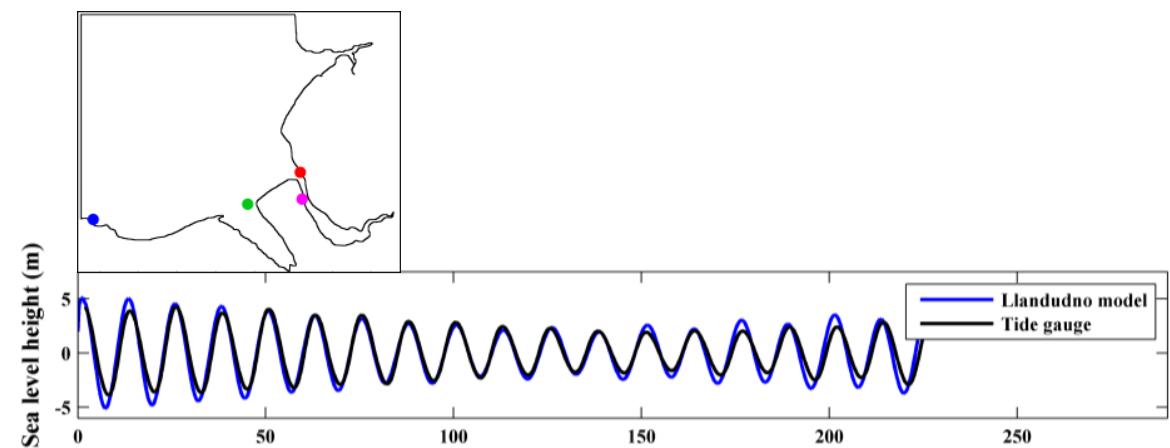

b)

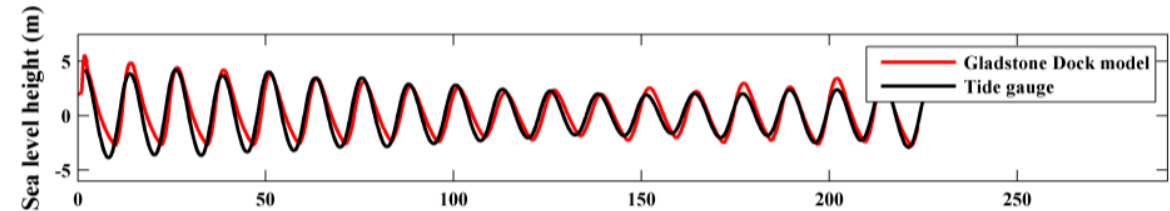

c)

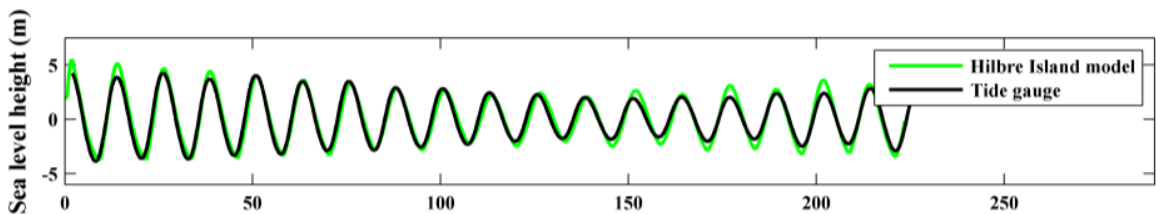

d)

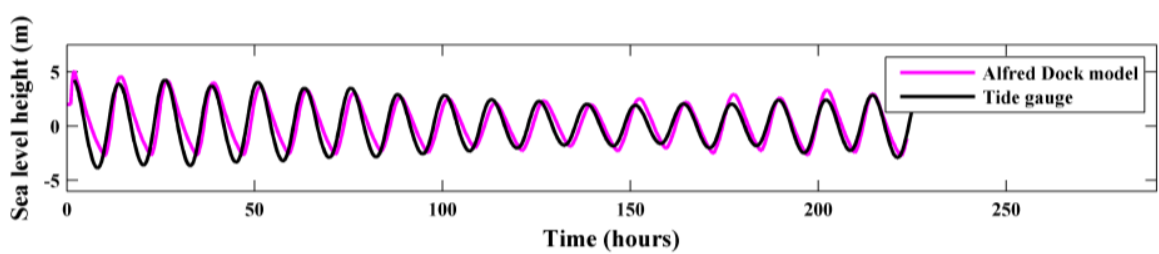

Figure 2. Tidal gauge sea level height comparison with modeled data at 4 locations in Liverpool Bay over a spring-neap cycle, a) Llandudno, b) Gladstone Dock, c) Hilbre Island, d) Alfred Dock. 
The sea surface currents for the 3D mesh are calibrated against high frequency radar data covering Liverpool Bay (Howarth et al. 2007). Two sites were selected for calibration (Figure 3), located between the three wind farm sites. Generally the model results show good agreement with the radar data in the velocity magnitude at both sites. However, a phase shift is seen during neap tides between modeled and radar data at both locations, but at spring tides the model and data are in phase. This is considered due to the fact that the model doesn't take into account wind effect which is significant to the surface flow in this region.

a)

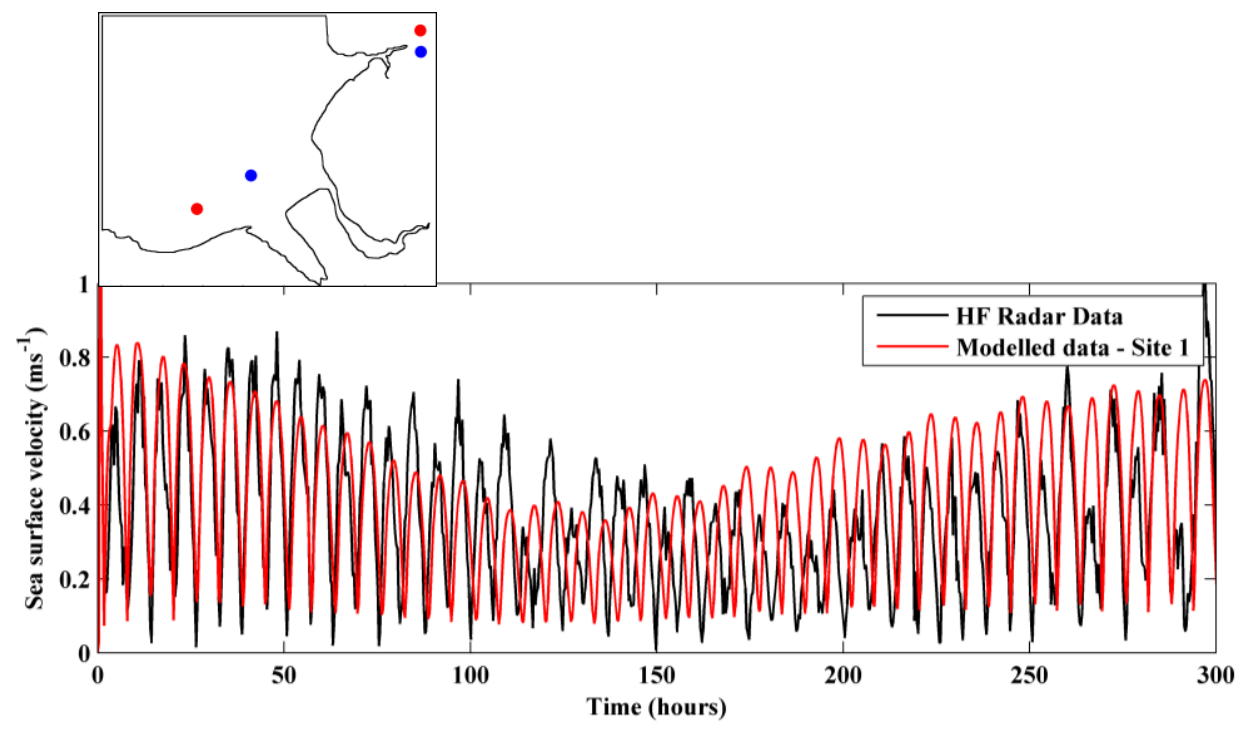

b)

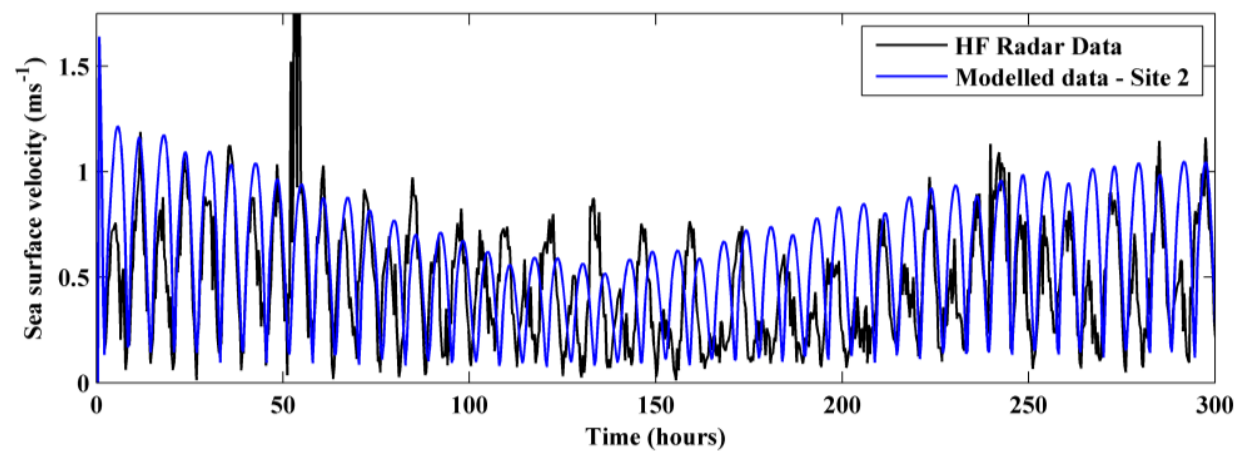

Figure 3. High frequency radar sea surface velocity measurements compared with model data at two locations in Liverpool Bay, a) site 1, b) site 2

\section{RESULTS}

The data generated from the models are cross-compared for the 2D and 3D scenarios and used to identify the impacts from the structure on both hydrodynamics and sediment transport.

Figure 4 shows the noticeable decrease in the depth averaged velocity occurs in the wake of each monopile foundation at the Burbo Bank site. This lee wake is greatest at the peak flood, where the wake tail can be seen stretched over 200-300 meters behind certain structures. However the effect of the wind farm array as a whole is fairly limited and no interaction can be seen between adjacent piles wakes. 


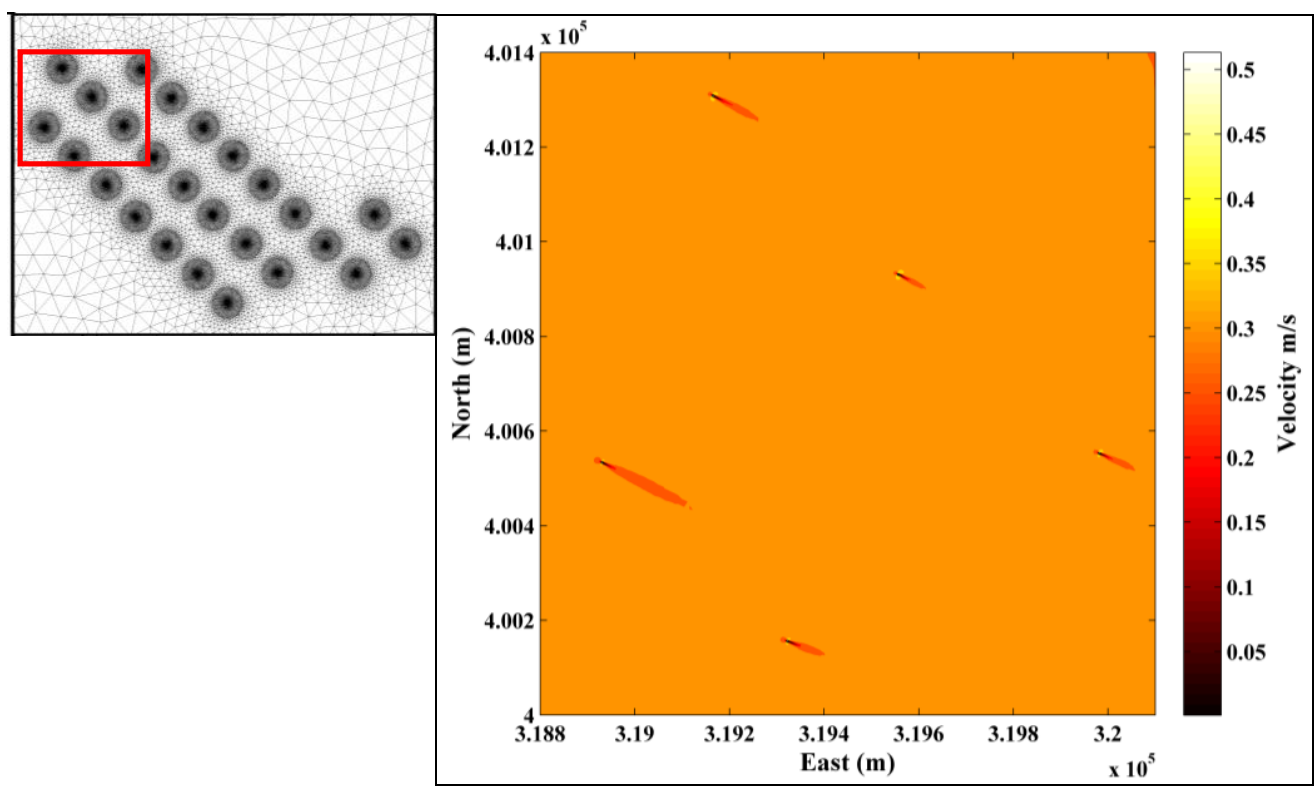

Figure 4. Depth averaged velocity over part of the Burbo Bank wind farm (highlighted|) for the 2D model run.

Figure 5 shows details of the flow structure behind an individual monopile during a peak flood spring tide computed by $2 \mathrm{D}$ and $3 \mathrm{D}$ runs. The $2 \mathrm{D}$ model run (Figure 5a) suggests a larger wake than the 3D model run (Figure 5b), although the deceleration pattern is similar in both cases. High velocities are seen at the side edges if the pile consistent with streamlines contracting. The 3D model run has larger acceleration than the $2 \mathrm{D}$ results, likely to influence scour hole formation.

a)

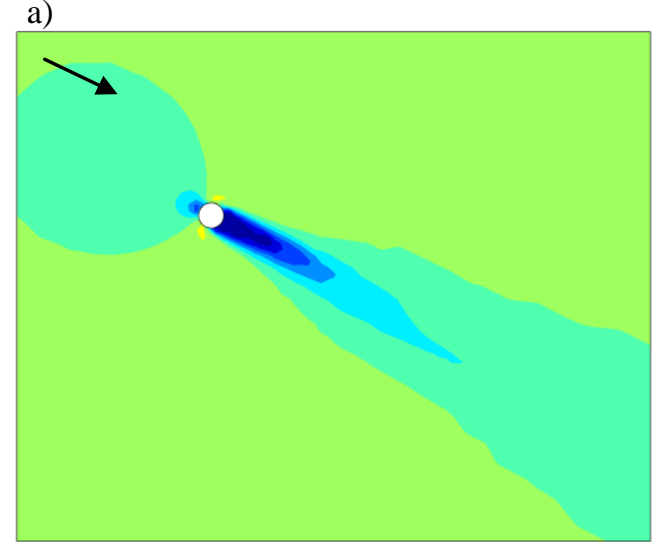

b)

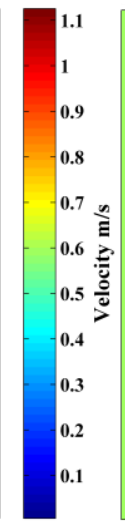

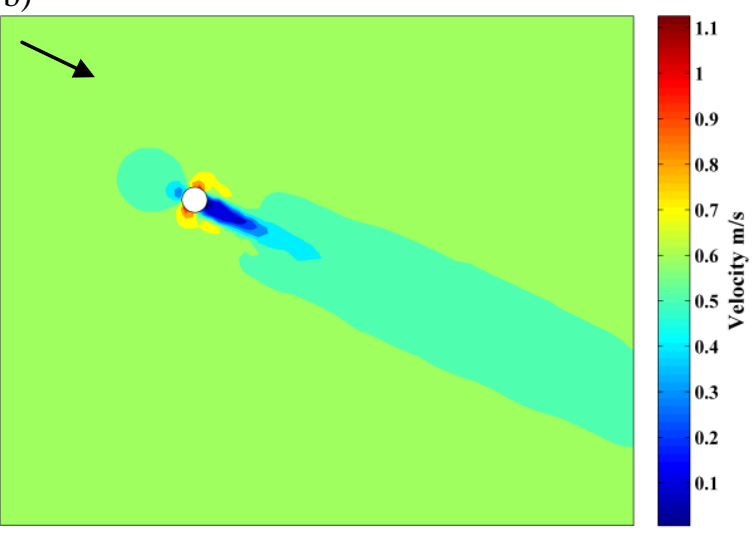

Figure 5. Peak flood vertically depth averaged velocity distribution around one monopile turbine at the North Hoyle wind farm for a) 2D model and b) 3D model. The arrow indicates the main current direction.

A similar pattern is seen at the peak ebb phase of the tide in Figure 6. The 2D (Figure 6a) case has greater shadowing effect of the monopile than the 3D (Figure 6b) case, although the difference in wake size is less pronounced than at peak flood (Figure 5). For both runs the lee wake is smaller in the ebb phase than flood phase, this is likely due to the water depth being lower in the ebb phase of the flow. Again the 3D model shows greater velocities at the sides of the pile than the 2D model run. 
a)

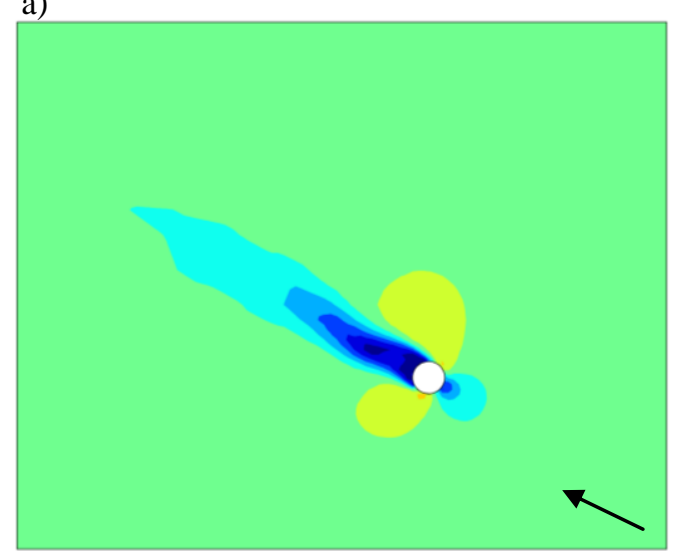

b)

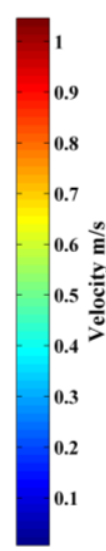

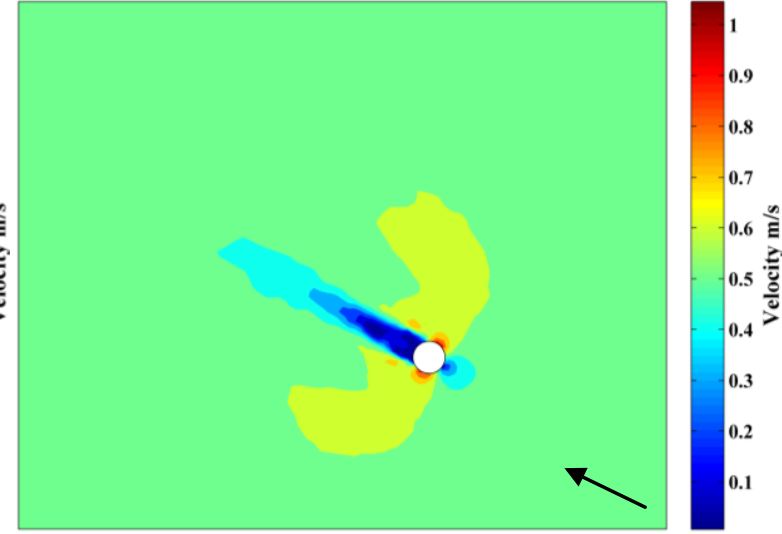

Figure 6. Peak ebb vertically depth averaged velocity distribution around one monopile turbine at the North Hoyle wind farm for a) 2D model and b) 3D model. The arrow indicates the main current direction.

As a 2D model is only able to provide depth averaged flow velocities, the complex flow structure known to occur around monopiles under tidal forcing cannot be identified. Results from the 3D model run however, shows marked differences between the bed and surface velocity distribution in Figure 7. At the surface (Figure 7a) the flow pattern structure is similar to that of the depth -averaged velocity, with a decrease in velocity in the wake of the pile and increased acceleration at the side of the pile. Near the bed (Figure 7b) the wake is much shorter, approximately the length of the pile diameter. The high velocities at the side of the pile become the prominent feature at the bed, which will significantly impact the scour pattern.

a)

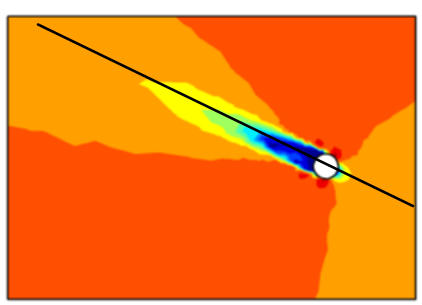

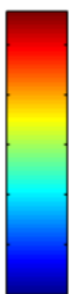

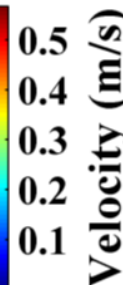

b)

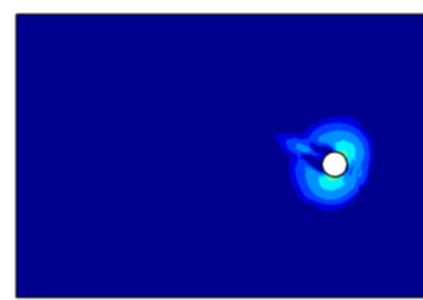

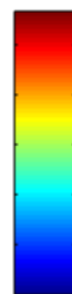

0.5
0.4
0.3
0.2
0.1

Figure 7. Velocity distribution at one monopile turbine at the North Hoyle wind farm for the 3D model run at a) the surface and b) the bottom. Black line indicates the cross-section for Figure 8.

A vertical cross-section is taken across the monopile for the 3D model run as indicated in Figure 7 , in order to create a vertical velocity profile of the influence of the monopile on the hydrodynamics (Figure 8). A logarithmic vertical profile is seen in front of the pile, followed by a reduced steep horizontal velocity profile to zero at the monopile wall. Behind the monopile there is a strong wake with low velocities behind the pile which gradual recovers to form a logarithmic profile around $30-40 \mathrm{~m}$ away from the monopile.

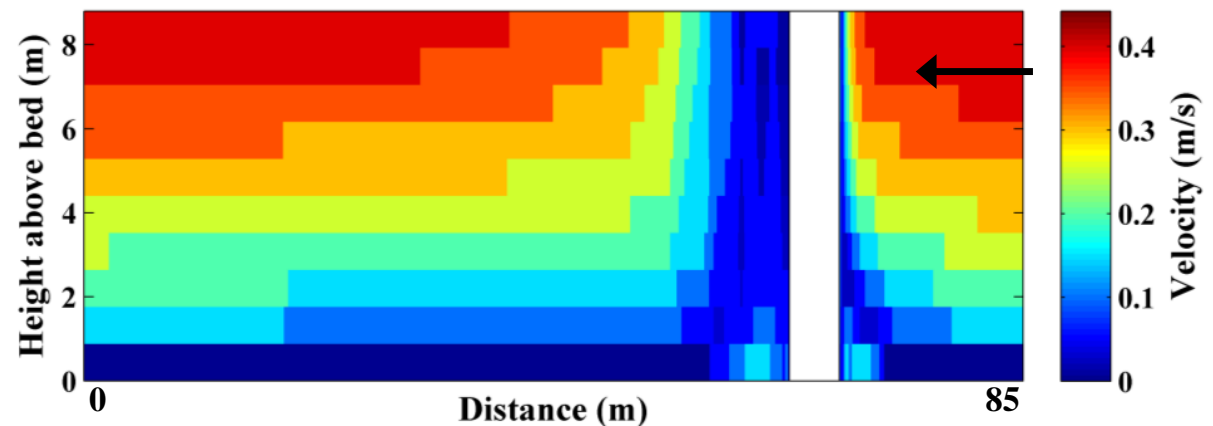

Figure 8. Vertical cross section velocity profile at one monopile turbine at the North Hoyle wind farm for the 3D model run. The arrow indicates the main current direction. 
Figure 9 shows the bed evolution over a 1.5 spring tides for both the 2D (Figure 9a) and 3D runs (Figure 9b). In both cases a scour pattern is seen around the monopile foundation, this is due to the acceleration of the flow leading to an increase in bed shear stress and subsequent increase in sediment transport. In both model runs an area of deposition is also apparent between the scour holes where sediment has been deposited from the eroded area. The 2D model run (Figure 9a) suggests an asymmetry in scour depth, which is due to the asymmetry in the size of the wake in the ebb and flood flow for the $2 \mathrm{D}$ run. The reason is considered as the $2 \mathrm{D}$ case relies on a logarithmic profile to determine the bed shear stress in the calculation of sediment transport, consequently, during the ebb the $2 \mathrm{D}$ result will have smaller bed shear stress force given a similar mean velocity profile as in the 3D case, which leads to less sediment transport.

a)

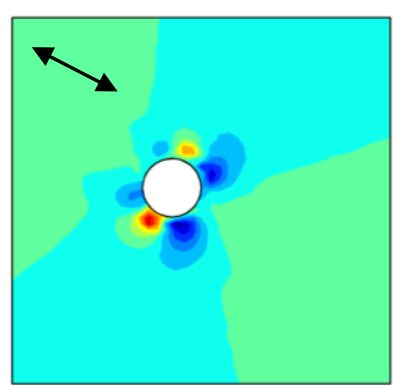

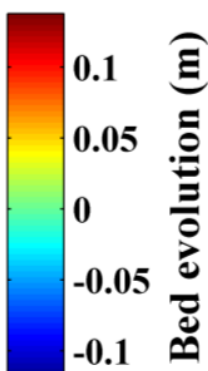

b)

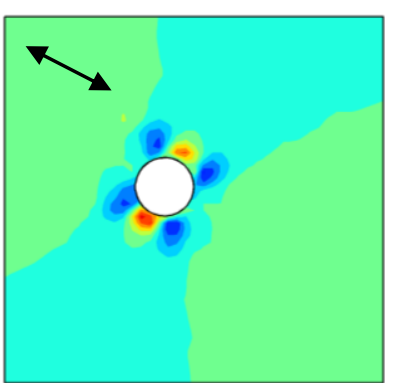

0.1

0.05

0

$-0.05$

$-0.1$

Figure 9. Bed evolution over 1.5 spring tides at one monopile turbine at the Burbo Bank wind farm for a) the 2D model and $b$ ) the 3D model run. Arrows indicate dominant tidal direction.

Figure 10 presents the bed evolution over 18 tides using the 3D model. The scour pattern becomes more apparent, with significant scour hole formation of up to $0.7 \mathrm{~m}$ depth. The area the scour hole covers has increased in comparison with the short model runs shown previously. The areas of deposition also have increased, but to a smaller magnitude than the scour depth increase, suggesting that the deposition area will be less significant over longer runs.

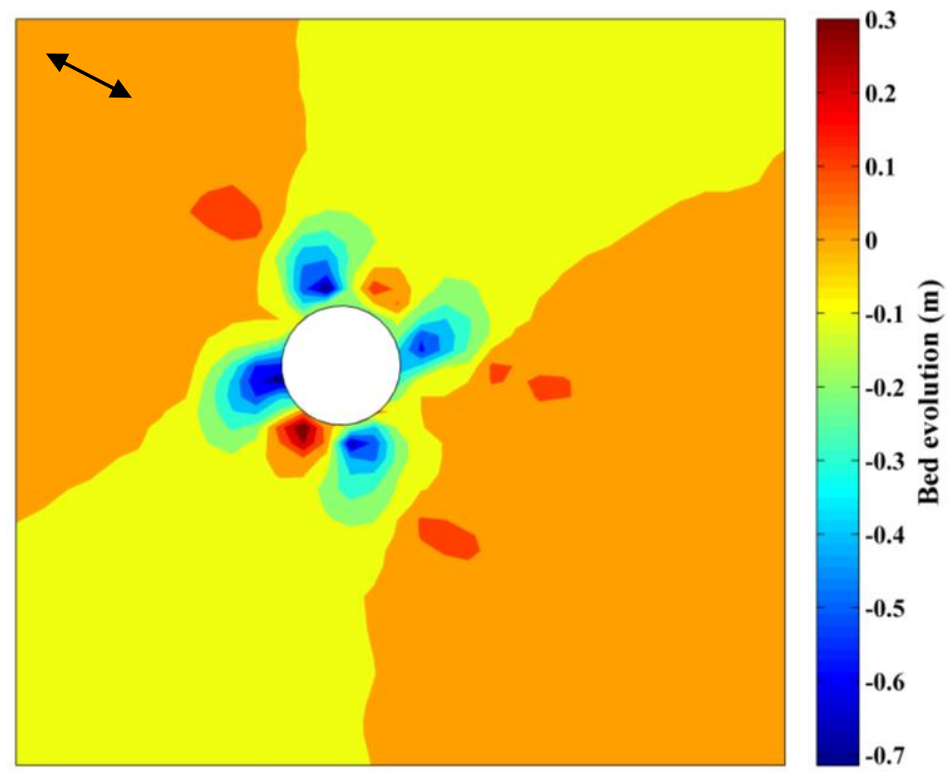

Figure 10. Bed evolution over 18 tides at one at one monopile turbine in the Burbo Bank wind farm for the 3D model run. Arrow indicates dominant tidal direction.

\section{CONCLUSION}

The 2D and 3D models are largely similar in the large scale with differences most prominent in the localized area around a monopile. At near scale around the monopile the 2D and 3D runs both give similar patterns of change in velocity, although it is more pronounced in the $2 \mathrm{D}$ case. The $3 \mathrm{D}$ model is 
shown to be capable of representing the complex vertical velocity patterns around the monopile. Scour patterns are similar to patterns seen in tank tests although areas of deposition are formed in both model runs.

\section{ACKNOWLEDGMENTS}

This project is partially supported by EPSRC UK through DTA and Hector Class 1b Access Funding, it is also acknowledged that data from the National Oceanography Centre, UK is used for model operation and calibration

\section{REFERENCES}

Egbert, G.D., and S.Y. Erofeeva. 2002. Efficient inverse modeling of barotropic ocean tides. Journal of Atmospheric and Oceanic Technology, 19, 183-204.

Howarth, M.J., Player, R.J., Wolf, J., and L.A. Siddons. 2007. HF radar measurements in Liverpool Bay, Irish Sea. Oceans 2007 - Europe. 1-6.

Lambkin, D.O., Harris, J.M., Cooper, W.S., and T. Coates. 2009. Coastal process modeling for Offshore Wind Farm environmental impact assessment: Best practice Guide. COWRIE Report

Moulinec, C., Denis, C., Pham, C-T., Rougé, D., Hervouet, J-M., Razafindrakoto, E., Barber, R.W., Emerson, D.R., and X-J. Gu. 2011. TELEMAC: An efficient hydrodynamic suite for massively parallel architectures. Computers \& Fluids, 51, 30-34.

Polton, J.A., Palmer, M.R., and M.J. Howarth. 2011. Physical and dynamical oceanography of Liverpool Bay, Ocean Dynamics, 61, 1421-1439.

Sumer, B.M., and J. Fredsøe. 2002.The mechanics of scour in the marine environment. Advanced series on Ocean Engineering. World Scientific.

Whitehouse, R. 1998. Scour at Marine Structures. Thomas Telford. 